\title{
Distribution of RNA M. Leprae Household Contact in Endemic Area Indonesia
}

\author{
A. Rizki Amelia \\ Lecturer of Department of Public Health, Universitas Muslim Indonesia
}

\begin{abstract}
Background and Objective: Chronic leprosy disease is caused by the transmission of Mycobacterium leprae bacilli, and leprosy is still as an enigmatic disease which is not fully understood. In terms of the national level, leprosy disease in Indonesia remains a public health problem. 16S rRNA gene is a gene that encodes which codes the $16 \mathrm{~S}$ part of the ribosome and it has specific nucleotides and can specifically be used to detect the cases of leprosy.
\end{abstract}

Materials and Method: This study was classified as the observational study using a case-control research design. The total samples were 81 individuals that consisted of 27 leprosy patients (the case group) and 54 non-leprosy patients (the control group). Analysis of $16 \mathrm{~S}$ rRNA gene expression was conducted using the RFLP-PCR method to detect the risk of leprosy.

Results: All samples of swabs of ear lobes for the case group (27 samples) were definitely positive infected by $M$. leprae and 2 dust samples (7\%) collected from houses of the case group showed positive infected by M. leprae bacilli, i.e. S05 and S09 respectively. Of all samples of dust collected from houses of non-leprosy patients (the control group), 4 dust samples (14\%) was positive infected by Mycobacterium leprae, i.e. $\mathrm{C} 03, \mathrm{C} 05, \mathrm{C} 09, \mathrm{C} 11$ respectively, and 2 non-leprosy patients were infected by M. leprae due to close social interactions with leprosy patients.

Conclusion: Dust medium and close social interactions were the causal factors for the transmission of leprosy disease. Therefore, it is suggested to conduct strict control to prevent the widespread of leprosy disease by keeping the cleanliness of houses at the local areas and the surrounding environment as well as the caution to do social interactions with leprosy individuals.

Key words : leprosy patients, $16 \mathrm{~s} r R N A$ gene, RFLP-PCR

\section{Introduction}

Leprosy is a chronic disease due to infections by Mycobacterium leprae that first attacks peripheral nerves and the upper respiratory tract. Clinical manifestation of the diseases varies greatly with different spectrum between two clinical forms of leprosy and tuberkuloid from lepramatosa. ${ }^{1}$

Although there is a descending trend of new cases, leprosy disease is still considered as a health problem in

\section{Corresponding Author}

\section{A. Rizki Amelia}

email: kikiarizkiamelia@yahoo.co.id

6285215325728 some countries, including India, Brazil, and Indonesia. ${ }^{2}$

Clinical manifestation of the disease varies widely among individuals. The transmission of $M$. leprae not only consider the cycle of transmission in the form of the source of leprosy disease, contact with the host, but also it is important to consider the source of infection., bacterial virulence, frequency of contacts and the characteristics of the host, including his/her immunity, specific immunity, age, sex and nutritional status and other factors. ${ }^{3}$

16S rRNA gene encodes a ribosomal RNA in a small sub-unit of the ribosome and it has a distinct nucleotide sequence in each bacterium. ${ }^{5}$ In addition, $16 \mathrm{~S}$ 
rRNA gene is more stable and it is suitable to be used a specific molecular marker for the identification ${ }^{6}$ of $16 \mathrm{~S}$ rRNA gene in bacteria (its existence is always retained in any conditions) and has identical characteristics in all organisms.

The $9.1 \%$ sequence difference contrasts sharply with the $0.005 \%$ difference uncovered by genome sequencing and multi-locus genotyping between M. leprae strains worldwide. To explore whether this novel leprosy pathogen is present in China, we analyzed 171 leprosy skin biopsy tissue samples from patients in different provinces of China by using nested $\mathrm{PCR}^{21}$

Based on the problem background as stated above, this study aims to assess the distribution of leprosy disease using the PCR method through the transmission of $M$. leprae at the local settlements by examining samples collected from swabs of leprosy individuals and dust medium and identification of social interactions (household contact) among leprosy patients and nonleprosy patients at the study area.

\section{Materials and Method}

\section{Samples of the study}

The study was classified as population in this study as the observational study using a case-control research design. The population in this study consisted of both the case group and control group. The case group was leprosy patients (BTA+), whereas, the control group was non-leprosy patients in Makassar municipality. Statistical analysis for both the case group and the control group was done using the Lameshow formula.

This study was classified as the observational study in which the authors did not control the assignment of treatments by using a case-control research design where the exposures to risk factors for the case group were compared to exposures for the control group. Samples in this study were leprosy patients (BTA+) and non-leprosy patients (BTA-) in Makassar municipality. The total samples were 81 individuals that consisted of 27 leprosy patients as the case group and 54 non-leprosy patients as the control group.

\section{Statement of Ethics}

All experimental procedures for the treatment of individuals as the samples in this study were reviewed and approved by the Research Ethics Committee of Medicine Faculty, Hasanuddin University

\section{Results}

\section{Distribution of leprosy disease for both the case} group and the control group

Dust medium and close social interactions (household contact) were identified in the distribution of leprosy disease for both the case group to identify the transmission of Mycobacterium leprae bacilli. The transmission of $M$. leprae is classified into three categories, i.e. detection of samples of swabs of ear lobes and dust samples from houses for the case group, detection of dust samples collected from houses of nonleprosy patients and examination of infected non-leprosy patients by $M$. leprae due to close social interactions (household contact) with leprosy patients. The three examination categories are shown in the following tables.

Table 1. Results of examination of M.leprae from samples of swabs of ear lobes in a slit skin smear for 27 leprosy patients $($ BTA + ) and dust samples collected from houses of 27 leprosy patients (the case group).

\begin{tabular}{llll}
$\begin{array}{l}\text { No. of } \\
\text { Samples }\end{array}$ & $\begin{array}{l}\text { M. } \\
\text { Leprae in } \\
\text { Samples }\end{array}$ & $\begin{array}{l}\text { Swabs of } \\
\text { Ear Lobes }\end{array}$ & $\begin{array}{l}\text { Dust } \\
\text { Samples }\end{array}$ \\
\hline 5 & S05 & Positive (+) & Positive (+) \\
9 & S09 & Positive (+) & Positive (+) \\
\hline
\end{tabular}

As shown in Table 1, results of examination of $M$. leprae bacilli in swabs of ear lobes of leprosy patients (the case group) from a slit skin smear showed that all leprosy patients were positive infected by M.leprae, and there were 2 dust samples (7\%) collected from houses for the case group showed positive contained M.leprae bacilli, i.e. S05 and S09. Houses of all leprosy patients are commonly next to each other within the average distance of $25 \mathrm{~m}$, whereas, the average distance for other houses are $50 \mathrm{~m}$ 
Table 2. Results of examination of M.leprae from dust samples collected from houses of non-leprosy patients (household contact).

$\begin{array}{lll}\text { No. of Samples } & \text { M. leprae in } & \text { Results of } \\ & \text { Dust Samples } & \text { Examination }\end{array}$

\begin{tabular}{lcc}
\hline 3 & C03 & Positive (+) \\
5 & C05 & Positive (+) \\
9 & C09 & Positive $(+)$ \\
11 & C11 & Positive $(+)$ \\
\hline
\end{tabular}

Of the 27 dust samples collected from houses of non-leprosy patients in Table 2, 4 dust samples (14\%) were positive contained $M$. leprae, i.e. C03, C05, C09, C11 respectively. This incidence was caused by relatively close distance between houses of non-leprosy patients and houses of leprosy patients (household contact) with the average distance of their houses is approximately $20 \mathrm{~m}$.

Analysis of the 16S rRNA gene using the PCR method

Results of PCR amplification and sequencing of 16S rRNA genes in the study samples derived from agarose gel electrophoresis of 16S rRNA genes were shown in the three following figures.

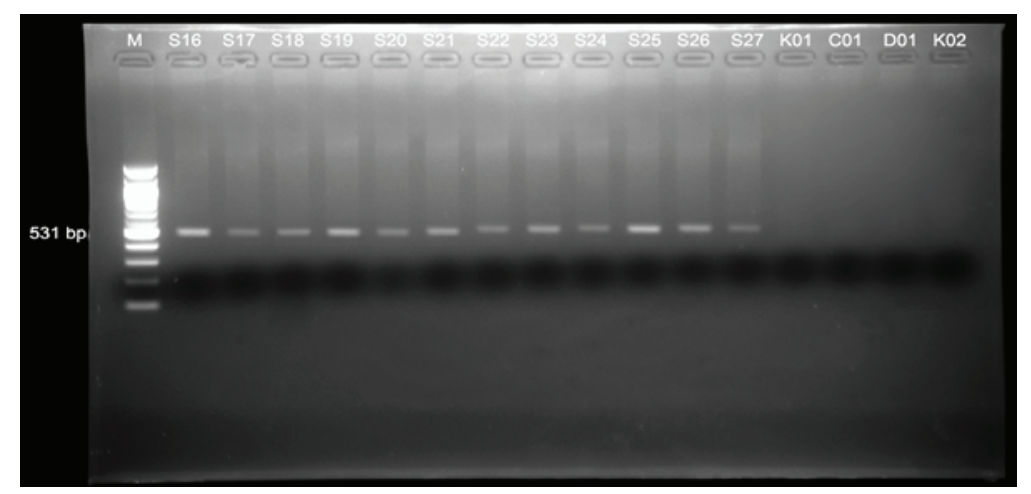

Figure 1. Results of agarose gel electrophoresis of 16S rRNA genes in the samples of leprosy individuals.

In Figure 1, results of agarose gel electrophoresis of 16S rRNA genes in the amplification of Mycobacterium leprae genes showed positive infection at 531 bp for the samples of S16, S17, S18, S19, S20, S21, S22, S23, S24, S25, S26, S27 respectively.

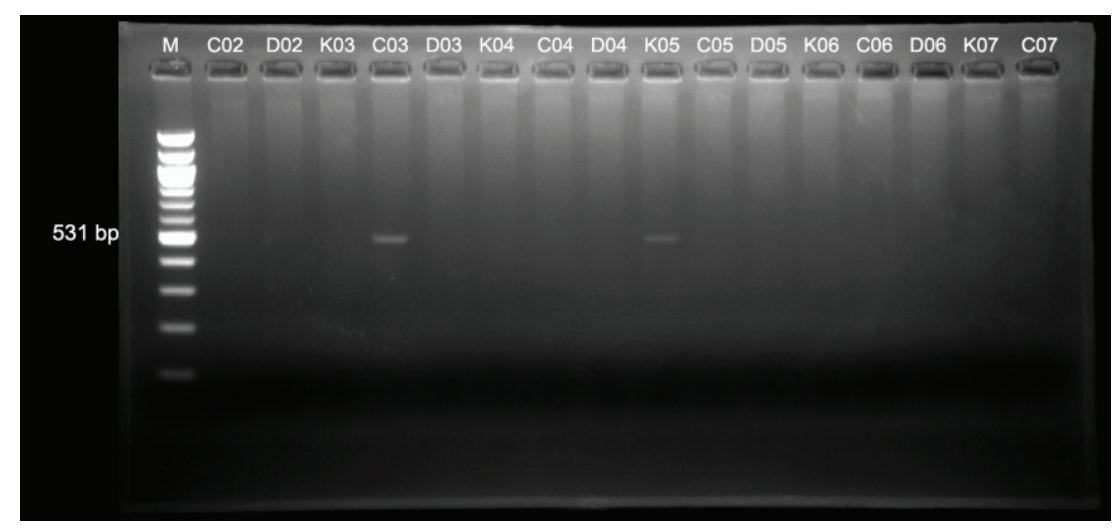

Figure 2. Results of agarose gel electrophoresis of 16S rRNA genes in dust samples. 
As shown in Figure 2, results of agarose gel electrophoresis of 16S rRNA genes in dust samples collected from houses at $531 \mathrm{bp}$ for the $\mathrm{C} 03$ sample, whereas, dust samples for non-leprosy individuals (BTA -) at $531 \mathrm{bp}$ for the K05 sample.

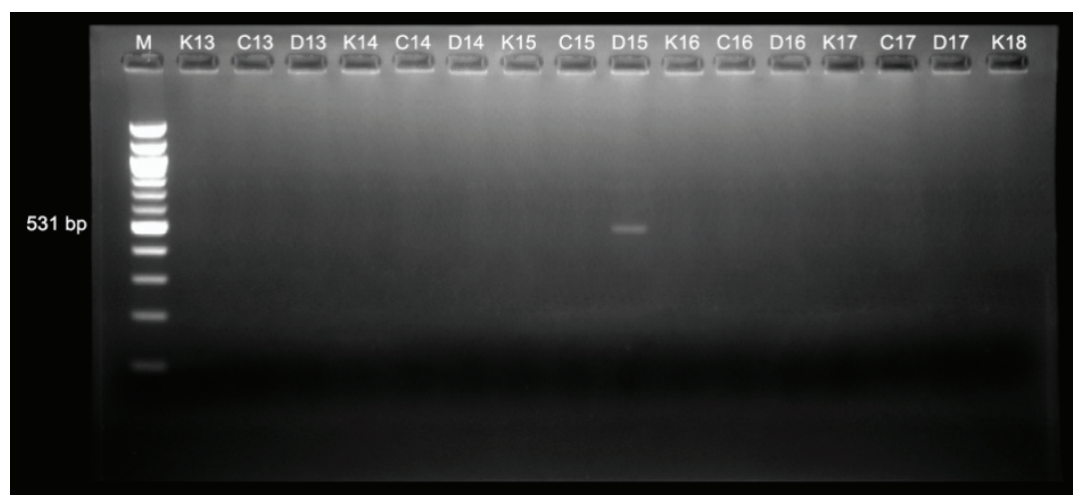

Figure 3. Results of agarose gel electrophoresis in dust samples that contained M. Lepra in the control group infected by $M$. leprae.

In Figure 3, results of agarose gel electrophoresis of 16S rRNA genes for non-leprosy patients (the control group) at $531 \mathrm{bp}$ for the D15 sample.

From the quantitative analysis for all samples, distribution of leprosy disease through the transmission of $M$. leprae based on the examination of dust samples and household contact is shown in Table 4.

Table 4. Distribution of leprosy disease through the transmission of $M$. leprae in dust samples and household contact.

\begin{tabular}{|c|c|c|c|c|c|c|c|c|}
\hline \multirow{2}{*}{ Dust } & \multicolumn{2}{|c|}{$\begin{array}{l}\text { Leprosy Patients } \\
\text { (BTA +) }\end{array}$} & \multicolumn{2}{|c|}{$\begin{array}{l}\text { Household } \\
\text { Contact (HC) }\end{array}$} & \multicolumn{2}{|c|}{$\begin{array}{l}\text { Household } \\
\text { Contact (HHC) }\end{array}$} & \multicolumn{2}{|c|}{ Total } \\
\hline & $\mathrm{n}$ & $\%$ & n & $\%$ & $\mathbf{n}$ & $\%$ & $\mathbf{n}$ & $\%$ \\
\hline Positive & 2 & 7.41 & 4 & 50 & 2 & 25 & 8 & 100 \\
\hline Negative & 25 & 92.59 & 23 & 31.4 & 25 & 34.3 & 73 & 100 \\
\hline Total & 27 & 100 & 27 & 33.3 & 27 & 33.3 & 81 & 100 \\
\hline
\end{tabular}

\section{Discussion}

Leprosy is a chronic disease that mainly affects the periphal nerves and skin. It is caused by an acid bacillus Mycobcaterium leprae which was first described by Hansen in 1874. Although Mycobcaterium leprae was the first agent to be linked to an infectious disease, leprosy is still today as an enigmatic disease which is not fully understood. The contact is not limited to household relationships, but also social relationship ${ }^{3}$

Global standardized guidelines for the diagnosis and treatment of leprosy for the elimination of this disease have been available and the efforst to do prevention of this disease has been practiced for more than 2 decades 9 . Classical epidemiology and leprosy control program 
have frequently identified household contacts of patient as objects for higher risk of infections than the general populations, ${ }^{10,11,4}$, explanation or tools are not routinely in place for tracing the origins and relationship of these and remaining new cases ${ }^{12,13,23}$

There is no easy quick method for the reliable detection and identification of M.leprae in clinical samples. Acid fast staining is a common method to detect M.leprae in a slit skin smear, but this method lacks specificity and sensitivity. Although in vivo culture of M.leprae in mice is a possibility, this methodology is not suited within a large scale. The polymerase chain reaction (PCR) is a novel, quick and reliable method of detecting small number of organisms through the amplification of a species DNA sequences to a detectable level ${ }^{14}$

All leprosy patients (BTA+) analyzed in this study were definitely positive infected by $M$. leprae and 2 dust samples (7\%) collected from two houses for the case group showed positive contained M. leprae bacilli. They commonly stay at dirty areas. In addition, they have low consciousness on healthy life on how to keep the cleanliness of house and their surrounding environment.

There were 4 dust samples were positive contained $M$. leprae in houses of the non-leprosy patients due to relatively close distance of houses of non-leprosy patients and houses of leprosy patients (household contact). The local communities at the study area always close social relationship in daily activities. Such a social behavior with high interaction intensity increases the risk of transmission of leprosy disease, especially social interactions between leprosy and non-leprosy individuals who live under one house that enhance the transmission of M.leprae bacilli.

Most individuals in the category of leprosy have low level income and they stay at unsuitable settlements as the common socioeconomic and cultural problems in several developing countries. Moreover, their houses are witihin a relatively close distance. Social interactions among local families at the study area commonly occur at afternoon as the spare times as observed in their daily activities.

This study is in line with the study conducted by Massi et.al. at the Tukamasea Village Administration. ${ }^{17}$
46 dust samples collected from house in the leprosy endemic area were examined and they found 3 samples (6.52\%) were positive infected by M.leprae, and MLPA test from 144 person showed $48.6 \%$ positive (70 individuals) infected by M.leprae, but only 5 individuals (7.1\%) indicated positive infected by M. leprae who live in houses using the PCR method.

Another study reported the transmission of $M$. leprae from dust collected from houses using the PCR method, but no significant different between IgM antibody titers for individuals with infection of DNA M.leprae was positive in dust samples collected from houses and their study supported the transmission of M.leprae in endemic $\operatorname{area}^{15}$

Several studies show a correlation between higher incidents of leprosy with lower SES ${ }^{18,19-22}$. Individuals in the category of low socioeconomic are 3.35 times more likely having the risk of leprosy disease. Lower SES is also related to low level of education. Illiteracy and low level of education of less than eight years of schooling is associated with the increase of leprosy cases. Low level of education has been reported as the risk factor of leprosy in studies conducted in CE. ${ }^{16,19}$

\section{Conclusion}

Based on results of the analysis 16s rRNA expression using RFLP-PCR, it was concluded that all samples (27 samples) of swabs of ear lobes for the case group were definitely positive infected by $M$. leprae and 2 dust samples (7\%) from houses for the case group showed positive contained M. leprae bacilli, i.e. S05 and S09 respectively. Of all samples of dust collected from houses of non-leprosy patients (the control group), 4 dust samples (14\%) was positive contained Mycobacterium leprae, i.e. $\mathrm{C} 03, \mathrm{C} 05, \mathrm{C} 09, \mathrm{C} 11$ respectively, and 2 nonleprosy patients were infected by $M$. leprae due to close social interactions (household contact) with leprosy patients. It is suggested to conduct strict control of the distribution of leprosy disease to do preventive measures that include keeping the cleanliness of houses at the local areas and the surrounding environment the caution to do social interactions with leprosy individuals to minimize transmission of M.leprae at a wider scale.

Ethical clearance- Taken from Faculty ethical committee 
Source of Funding- Self

Conflict of Interest - Nil

\section{References}

1. Chin, J. "Control of communicable disease." 17ed, American Public Health Association, Washington DC. 2000.

2. World Health Organization. Global Leprosy Situation 2007b. WHO Weekly Epidemiol. 2007; 82: $225-232$.

3. Bear SM, van, Wit MYL de, Klatser PR. The epidemiology of Mycobcaterium leprae:recent insight FEMS Microbiol Lett. 1996; 136:221-230.

4. Bear SM van, Hatta. M., Klatser PR "Patient contact is the major determinant in incident leprosy. Implications for future control " Int. J. Leprosy 1999; 67: 119-128.

5. Yoshua Y, Yan W, Yuangang Y, Yan X, Huanying L, Xioman W, Nan W, Shuang L, Shanshan Z, Wenhong Z, Ying Z, Characterization of Mycobacterium leprae genotypes in ChinaIdentification of a new Polymorphism C251T in the 16S rRNA Gene. Plos One 2015; 10: 1-10.

6. Gonzales J. M. S.-J., C. "A Simple fluorimetric method for the estimation of DNA-DNA relatedness between closely related microorganisms by thermal denaturation temparatures. ." Extramophiles 2015; 9: 75-79.

7. Singh, V., Chaudhary, D.K., Mani. L. "Molecular characterization and modeling of secondary structur of 16S rRNA from Aeromonas veronii." International journal of applied biology and pharmaeutical technology 2012.

8. Hatta M. September 20-21. Application of Polimerase Chain Reaction (PCR) for detection of DNA Mycobactrium leprae from nassal swabs on leprosy patients. Proceddings of International Symposium of Biochemical and Moleculer Biological Approaches on Ageing; Bandung, Indonesia $1995 ; 19-20$.

9. Mannot, M.,N. Honore, N. Garnier, R. Arouz, J.Y. Copee, C. Lacroix, S. Sow, J.S. Spencer, R.W. Truman, D.L. Williams, R. Gelber, M. Virmond, B. Flageoul, S.N. Cho, B. Ji, A. PanizMondolfi, J. Convit, S, Young, P.E, Fine, V. Rosolfo, P.J. Brenan, and S.T. Cole. 2005. On the origin of leprosy. Science 308;1040-2. Epub
Medico-legal Update, July-September 2020, Vol.20, No. $37 \mathbf{7 5 5}$

2005/05/17. doi:308/5724/1040(pii)doi:10.1126/ science/1109759 PMID:15894530.

10. World Health Organization. Global leprosy situation, begening of 2008, Wkly. Epidemiolo. Rec. 2008; 83:293-300.

11. Cardona-Castro, N.J. Beltran -Alzate, and R. manrique- Harnandez, Survey to identifity Mycobacterium leprae- infected household contacts of patients from prevalent regions of leprosy in Colombia. Mem. Inst. Oswaldo Cruz 2008.; 103:332-336.

12. Cellona R.V..,G.P. Walsh, T. T. Fajardo, Jr.,R.M. Abalos, E.C. dela Cruz, L. Guido-Villahermosa, M.V. Felicio Belago, G.J. Steen bergen, and J.T Douglas.. Croos- Sectional assesment of ELISA reactivity in leprosy patient, contacts, and normal populations using the semisynthetic antigen natural disaccharide octyl bovine serum albumin (ND-O BSA) in Cebu, the Philippines. Int.J. Lepr. Other Mycobcat. 1993; Dis 61:192-198.

13. Deeps, P.D., B.V. Guedes, J.B. Filho, M.K. Andreatta, R.S. Marcari, and L.C. Rodrigues, Delay in the diagnosis of leprosy in the metropolitan region of Vitoria Brazil. Lepr. Rev. 2006; 77:4147.

14. Tadese Argaw, A.,E.J. Shannon, A. Assefa,F.S, Mikru, B. K. Mariam, and J.B. Malone, A geospatial risk assesment model for leprosy in Ethopia based on environmental thermal-hydrological regime analysis. Geospat Health. 2006. ; 1:105-113

15. Gillis. TP, Williams DL. Polymerase chain reaction and leprosy. Int. J. lepr, 1991; 59. 311-316.

16. Masse, N, Rizalinda, Kwenang A, Hatta.M, Identification of IgM antybodiby MLPA test and relationship with DNA Mycobacterium leprae from housedust in leprosy endemic ares Nusantara Medical Journal Science 2001; 22:319-323.

17. Kerr-Pontes LR, Barreto ML, Evangelista CM, Rodrigues LC, Heukelbech J, Feldmer H. Socioeconomic, environmental and behavioural risk factors for leprosy in Northeast Brazil : results of case-control study. Int J Epedemiol 2006; 35:994-1000.

18. Sales AM, Ponce de Leon A, Duppre NC, Hacker MA, Nery JA, Sarno EN, Penna ML Leprosy among patients contact: a multilevel study of risk factors. PLoS Negl Trop Dis 2011; 5:1013.

19. Cury MR, Paschoal VD, Nardi SM, Chierotti AP, 
Rodrigues Jr AL, Chiaravalloti-Neto F. Spatial analysis of leprosy incidence and associated socioeconomic factors. Rev Saude Publica 2012; 46:110-118.

20. Kerr-Pontes LR, Montenegro A, Barreto ML, Werneck GL, Feldmeier H. Inequality and leprosy in Nourthheast Brazil : an ecologcal study. Int J Epidemiol 2004; 33:262-269.

21. Han XY, Sizer KC. Velarde-Felix JS, Frias -CastroLo, Vargas-OcampoF, The leprosy agents Mycobacterium lepromatosis and Mycobacterium leprae in Mexico. Int J Dermatol 2012; 51(8);952-9. Epub 2012/07/14. doi:10.1111/
j.1365-4632.2011.05414.x;Pubmed Central PMCID:PMC3397401.

22. Owildan Wisudawan $B$, et al. Bioaerosol pollution in intensive-care unit of Dr. Wahidin Sudirohusodo Hospital Makassar: Morning and midday assessment. Enferm Clin. 2020. https://doi. org/10.1016/j.enfcli.2020.02.009

23. Stang, et al. Risk factor model for pulmonary tuberculosis occurrence in Makassar using spatial approach. Enferm Clin. 2020. https://doi. org/10.1016/j.enfcli.2019.10.105 